\title{
Exploration and Practice of Embedded Talent Training in Measurement and Control Technology and Instrument Specialty
}

\author{
Chen Haixiu',2, a, ${ }^{*}$, Chen Weifeng ${ }^{2}$, Liu Yunping ${ }^{2}$, Zhang Zijia ${ }^{2}$, Hou Yan² \\ ${ }^{1}$ Jiangsu Collaborative Innovation Center of Atmospheric Environment and Equipment Technology \\ (CICAEET), Nanjing University of Information Science \& Technology, Nanjing, China \\ ${ }^{2}$ School of Automation, Nanjing University of Information Science \& Technology, Nanjing, China \\ ahaix_chen@126.com
}

Keywords: Embedded talent training, Curriculum system, Practice training

\begin{abstract}
As an important part of the university-enterprise cooperation, the embedded talent training has played a significant role in the talent training. On the purpose of cultivating applied talents to adapt to the development of related industries, Nanjing University of Information Science \& Technology carried out the teaching reform of the embedded talent training with the cooperation of Jiangsu Ruipin Information Technology Co., Ltd. By constructing the curriculum system for embedded talent training, strengthening the construction of teachers' team, and improving the practice training conditions, the quality of the talent training has been comprehensively improved.
\end{abstract}

\section{Introduction}

With the development of China's higher education and the change of social demand for talents, the existing talent training model can't meet the actual needs of society, enterprises and students gradually ${ }^{[1]}$. Although students have a relatively complete professional theoretical system, they still lack the ability to solve practical problems, to complete teamwork and communicate well with others in engineering. Therefore, it is an inevitable requirement and fundamental measure for the development of education to construct an embedded talent training mode that meets the needs of society, integrates the respective advantages of schools and enterprises, and cultivates high-quality applied talents ${ }^{[2]}$. In order to comprehensively improve the quality of talent training, our school has reached strategic cooperation with Jiangsu Ruipin Information Technology Co., Ltd. since 2017. And the embedded talents training practice has been carried out in the major of measurement and control technology and instrument.

\section{General situation of measurement and control technology and instrument specialty}

The specialty of measurement and control technology and instrument in Nanjing University of Information Science \& Technology has been enrolled since 2004. After fifteen years of professional construction and development, this specialty in our school has reached a higher level. At present, the specialty of measurement and control technology and instrument is the key specialty of Jiangsu Province and China Meteorological Administration. This major trains high-level engineering and technical talents with basic theoretical knowledge, professional technical knowledge and application skills of natural science, engineering foundation, measurement control and instrument, and comprehensive design and development, system integration and application ability of electromechanical measurement and control system and electronic instrument ${ }^{[3]}$.

Since 2017, the Embedded Talents Training Project has been carried out by Nanjing University of Information Science \& Technology and Jiangsu Ruipin Information Technology Co., Ltd. With the support of industry associations and large-scale enterprises, the project closely combines the demand for talents in the transformation and upgrading of Jiangsu's industrial structure. And the project aims to build a collaborative education system and establish a new mechanism for industry enterprises to participate in professional construction and talent training in depth. The implementation of the 
project enables us to face the international frontier in the field of professional application, to cultivate high-quality, practical and compound talents who can meet the needs of relevant industry development, systematically master basic theory and applied knowledge, have innovative ability and international competitiveness ${ }^{[4-5]}$.

The project is guided by the demand for industrial talents. Through building a platform for school-enterprise cooperation, it jointly formulates professional reform programs and talent training programs. According to the needs of industrial career development ability, we should build a scientific and reasonable embedded curriculum system in line with the orientation of applied talents training, strengthen experimental practice, and strengthen students' innovation and entrepreneurship education.

Specifically, we adopt the "school-enterprise joint training" model for students. As soon as students enter the university, they are educated jointly by professional teachers in university and engineers from enterprises. Through entrance education, students can get a general understanding of academic career planning and professional knowledge system. And students can understand their professional prospects just after entering the university, so that they can have a clear plan for the next four years and future career.

Students study the theoretical basis courses in university in the first five semesters. And in the curriculum system, we embed the characteristic technology courses of Enterprise Engineering in the professional courses. School teachers are the main teaching staff in this process. And enterprises use the end of the semesters to increase the corresponding practical teaching content for students according to the needs of job skills. In the last three semesters, enterprise teachers undertake the practical teaching work of embedded core courses, enterprise project training, and graduation practice and so on. Enterprises also undertake employment recommendation. Graduation design will be completed mainly under the guidance of the enterprise with assistance of the school.

\section{Construction of embedded talent training course system}

The formulation of embedded talent training program is based on the mature professional training program of measurement and control technology and instrument specialty in 2016. According to the graduation needs of students, the corresponding embedded curriculum system is constructed. And the complete embedded talent training program is constructed through the construction of embedded teachers' team and training bases inside and outside school.

Embedded curriculum system is mainly composed of public basic courses, subject basic courses, professional courses and centralized practice links. The credit ratio of public basic courses, subject basic courses, professional courses, and centralized practice links is $41.1 \%, 12.5 \%, 20 \%$, and $26.4 \%$ respectively.

In this embedded curriculum system, enterprises customize and develop curriculum modules and project-based courses for students majoring in measurement and control technology and instrument. The embedded characteristic courses mainly include entrance education, Linux operating system, Principle and Design of Intelligent Hardware System, Intelligent Hardware Communication Technology, The Programming Technology of MCU and its Application, Course Exercise of Intelligent Hardware System, Project Practice, Course Exercise of Intelligent Hardware Communication, Graduation Design, Graduation Practice, Lectures on Professional Literacy, Graduation Education and so on. The embedded enterprise curriculum module and professional curriculum are organically linked to achieve complementary advantages in order to strengthen the cultivation of professional comprehensive quality. And therefore we can train high-level technicians who have the basic knowledge and skills of embedded system application and can develop the corresponding embedded system, and can be engaged in technology development and management in the field of embedded system application. 


\section{Construction of embedded teachers' team}

The school formulates special policies for the introduction and training of teachers for the training of embedded talents, encourages teachers to devote themselves to the cause of embedded talents training. A group of high-level professional teachers and part-time enterprise teachers have been introduced into university to form a pluralistic, open and double-qualified teachers' team.

The school promotes the cultivation of double-qualified teachers actively, encourages teachers to participate in the project development of enterprises, promotes full-time teachers to exchange and learn in the relevant industries and meteorological industries, and establishes a system and mechanism for teachers from related industries and meteorological industries to teach part-time in measurement and control specialty. The school also pays attention to improving the professional level and international vision of the teaching staff, and appoints outstanding young teachers to visit or engage in post-doctoral research in famous universities and scientific research institutions abroad, so as to continuously improve their teaching, scientific research level and service ability to cultivate professional and characteristic talents.

At the same time, the school has trained a group of discipline leaders with high visibility in China and international influence, and a group of young and middle-aged academic leaders with leading level of teaching and scientific research in the province and certain influence in China. Young teachers are guided by a tutorial system, with experienced and famous teachers as tutors to instruct them how to improve teaching skills. On this basis, the discipline leaders and academic leaders play a full role in encouraging and leading young teachers to write papers, declare various teaching and research projects actively, improve their teaching and research capabilities constantly, and integrate them into teaching and research teams as soon as possible.

The cooperative enterprise also holds a "National Excellent Engineers" training course for teachers every year. The training content is the latest research and development products and teaching results of the enterprise, and the course will show how these products and results are applied to the classroom of universities. Teachers can master experimental teaching cases through training, make the teaching content meet the real requirements of enterprise development, and closely integrate with industry applications. Furthermore, the training promotes the project-driven curriculum reform, improves the level of teachers' practical teaching, and speeds up the construction of teachers' team.

Through these measures, the allocation and quality of professional teachers have been greatly improved, which further promotes the progress of embedded talent training project.

\section{Improvement of the practice training conditions}

Through strengthening the reform and innovation of experimental teaching content, methods, means and experimental teaching mode, promoting the construction of teaching instruments and equipment and the reform of management mechanism in school, the hardware and software of experimental teaching have been obviously improved, which lays a good environmental foundation for the cultivation of students' innovative ability and improves the professional experimental teaching conditions.

The School of Automation, where the measurement and control specialty is located, has vigorously promoted the construction of teaching and scientific research platform. There are Jiangsu Automation Experimental Teaching Center, Jiangsu Internet of Things Engineering Practice Education Center, Jiangsu Key Laboratory of Data Analysis Technology, Jiangsu Cooperative Innovation Center of Atmospheric Environment and Equipment Technology in the school. And there are three central and local research platforms, and six university-enterprise research institutes in the school. The school is equipped with mainframe, ground standard weather station, PIONEER3-AT robot, wind tunnel and other advanced instruments and equipment, which provides an important guarantee for the cultivation of students' practical innovation ability.

At the same time, the specialty of measurement and control takes advantage of the co-construction of China Meteorological Administration and the university, and carries out innovative practice of 
meteorological characteristics. A series of practice bases have been established to provide students with distributed temperature, humidity, smoke and other data acquisition experiments, wireless sensor network application layer protocol development experiments, ARM series microcontroller related experiments, and environment-oriented sensor node design (including product appearance, mechanical structure, material design, etc.) training. These activities have trained students' practical experience in industrial field application and laid a solid foundation for their future work.

\section{Reform of institutional mechanisms}

In the process of revising the professional teaching plan, we have formed a core curriculum group with industry characteristics by improving the basic curriculum and determining the core curriculum. By reasonably expanding the professional orientation, integrating the obsolete specialized elective courses and adding new and practical specialized courses, the professional settings are more scientific and more in line with the needs of social and economic development. At the same time, we continue to strengthen the basic, practical, comprehensive and innovative requirements of professional training. And the comprehensive competitiveness of talent training has been improved.

\section{Conclusion}

It is one of the fundamental tasks of colleges and universities to cultivate innovative and applied undergraduate talents with high quality. Appropriate talent training mode is the fundamental guarantee to achieve this goal. Embedded talent training mode is of great significance to guide universities to run their own characteristics and improve the expectations of higher education, and it is also an inevitable requirement for the development of higher education.

\section{Acknowledgment}

This research was financially supported by Nanjing University of Information Science \& Technology (Grant NO. 2017JY036 and NO. 201910300149Y).

\section{References}

[1] Zheng Haiying, Yang Huijun, Yin Lunhai, Research and Practice on the Training Model of Applied Talents of Measurement and Control Technology and Instrument Specialty, China Modern Educational Equipment, vol.10, pp. 43-45, 2017.

[2] WU Yucheng, SONG Yan, CHEN Donghua, HAO Genyan, SHAO Qinyan, Construction and Practice of the Educational System of All-staff Cooperation and Practice under the Background of the Emerging Engineering, Social Sciences Journal of Universities in Shanxi, vol.6, pp. 66-70, 2019.

[3] BAO Zhen-hua, Exploration of Multi-dimensional"embedded"Talent Cultivation Modes, Journal of Wuhan Polytechnic, vol.16, pp. 34-38, 2017.

[4] Dai Hongwei, Research and Exploration on the Embedded Talent Training Mode Based on College -Enterprise Collaboration, The Science Education Article Collects, vol. 11, pp. 56-58, 2017.

[5] Wu Yufeng, Bai Feng'e, Exploration and practice of embedded talent training in colleges and universities, Experimental Technology and Management, vol. 35, pp. 172-176, 2018. 